Abstracta Iranica

Revue bibliographique pour le domaine irano-aryen

Volume 37-38-39 | 2018

Comptes rendus des publications de 2014-2016

\title{
Jason Mokhtarian, David Bennett (eds.). Religious trends in late ancient and early Islamic Iran
}

\section{Christelle Jullien}

\section{(2) OpenEdition}

12 Journals

\section{Édition électronique}

URL : http://journals.openedition.org/abstractairanica/43415

DOI : 10.4000/abstractairanica.43415

ISBN : 1961-960X

ISSN : 1961-960X

Éditeur :

CNRS (UMR 7528 Mondes iraniens et indiens), Éditions de l'IFRI

Référence électronique

Christelle Jullien, « Jason Mokhtarian, David Bennett (eds.). Religious trends in late ancient and early Islamic Iran », Abstracta Iranica [En ligne], Volume 37-38-39 | 2018, document 3, mis en ligne le 30 décembre 2018, consulté le 26 septembre 2020. URL : http://journals.openedition.org/ abstractairanica/43415; DOI : https://doi.org/10.4000/abstractairanica.43415

Ce document a été généré automatiquement le 26 septembre 2020.

Tous droits réservés 


\title{
Jason Mokhtarian, David Bennett (eds.). Religious trends in late ancient and early Islamic Iran
}

\author{
Christelle Jullien
}

\section{RÉFÉRENCE}

Jason Mokhtarian, David Bennett (eds.). Religious trends in late ancient and early Islamic Iran. Iranian Studies 48/1, 2015. ISSN 0021-0862 (version papier) et 1475-4819 (web). En ligne : http://www.tandfonline.com/toc/cist20/48/1\#.VK0o6R1b8WM

1 Le fascicule 48/1 de la revue Iranian studies chez Routledge est un numéro thématique sur les courants religieux de l'Iran préislamique et des débuts de la conquête arabe. Il comprend 5 articles: le premier, intitulé « East Syrian Bishops, Elite Households, and Iranian Law after the Muslim Conquest " par R. Payne (p. 5-32), explore les relations juridiques entre chrétiens et mazdéens au début de l'ère islamique. Il s'agit d'une présentation synthétique d'un des aspects développés dans son ouvrage A State of Mixture: Christians, Zoroastrians, and Iranian Political Culture in Late Antiquity paru la même année. Il montre comment les évêques syro-orientaux se sont appropriés des domaines de la jurisprudence civile traditionnelle, notamment sur les questions du mariage, des héritages et de la propriété, soulignant l'influence de système juridique et la culture iranienne sur la communauté chrétienne, spécialement l'aristocratie chrétienne bien acculturée. S. Thrope aborde un sujet d'angélologie judaïque en milieu iranien: «Unnecessary Angels: Jewish Angelology in the Škand Gumānīg Wizār» (p. 33-53). L'article Kh. Rezakhani (« Mazdakism, Manichaeism and Zoroastrianism: In Search of Orthodoxy and Heterodoxy in Late Antique Iran », p. 55-70) reprend un sujet souvent débattu, celui de la notion d'orthodoxie et d'hétérodoxie dans le mazdakisme, le manichéisme et le zoroastrisme. Pour l'A., cette désignation d'hétérodoxie pour des mouvements socio-religieux en Iran dans l'Antiquité tardive serait inappropriée et sans doute post-sassanide. M. Canepa (« Seleukid Sacred Architecture, Royal Cult and the 
Transformation of Iranian Culture in the Middle Iranian Period», p. 71-97) analyse l'influence de l'architecture séleucide sur la culture religieuse et royale iranienne jusqu'à la fin de la dynastie sassanide, après l'héritage achéménide. Cette transformation de la culture iranienne s'effectua selon l'A. à la fois en rupture mais aussi en continuité avec les traditions babyloniennes, achéménides ou macédoniennes, puisque les Séleucides avaient eux-mêmes intégré diverses traditions culturelles, architecturales et religieuses. Un dernier article enfin regarde la notion d'infidélité dans les textes du zoroastrisme (spécialement le Livre des mille jugements et le Dēnkard III) appliqué aux juifs, aux chrétiens et aux musulmans par J. Mokhtarian ("The Boundaries of an Infidel in Zoroastrianism: A Middle Persian Term of Otherness for Jews, Christians, and Muslims ", p. 99-115) : l'A. insiste sur les mises en contexte de cette terminologie (le terme agdēn est souvent usité pour désigner ces différents groupes minoritaires), qui apparaît généralement lorsque les mazdéens se trouvent menacés dans leur identité, dans un contexte de conversion du zoroastrisme, de problèmes posés par des inter-mariages ou des cas de mixité culturelle par exemple. Tous les articles ont été mis en ligne en libre accès.

\section{AUTEURS}

\section{CHRISTELLE JULLIEN}

CNRS, Mondes iranien et indien, Paris 